\title{
Prior Pro-inflammatory Polarization Changes the Macrophage Response to IL-4
}

Erin M. O’Brien* and Kara L. Spiller*

*School of Biomedical Engineering, Science, and Health Systems, Drexel University, Philadelphia, PA

Running title: Effects of M1 activation on subsequent M2 polarization

Summary sentence: M1 macrophages that are switched to an M2 phenotype exhibit a distinct functional phenotype compared to M2 macrophages derived directly from unactivated (M0) macrophages.

Key words: macrophage polarization; inflammation; tissue repair

Corresponding author: Kara L. Spiller; 3141 Chestnut Street, Bossone 712, Philadelphia, PA 19104; (215) 571-3822; kls35@drexel.edu 
bioRxiv preprint doi: https://doi.org/10.1101/2021.04.06.438673; this version posted April 8, 2021. The copyright holder for this preprint (which was not certified by peer review) is the author/funder, who has granted bioRxiv a license to display the preprint in perpetuity. It is made available under aCC-BY-NC-ND 4.0 International license.

\section{Abbreviations}

IFNY interferon-gamma

IL-4 interleukin-4

LPS lipopolysaccharide

MTT 3-(4,5-dimethylthiazol-2-yl)-2,5-diphenyltetrazolium bromide

PDGF-BB platelet-derived growth factor BB

SDF-1a stromal-derived factor-1 alpha

VEGFA vascular endothelial growth factor $A$ 


\section{Abstract}

Tissue repair is largely regulated by diverse macrophage populations whose functions are timing- and context-dependent. The early phase of healing is dominated by proinflammatory macrophages, also known as M1, followed by the emergence of a distinct and diverse population that is collectively referred to as M2. The extent of the diversity of the M2 population is unknown. M2 macrophages may originate directly from circulating monocytes or from phenotypic switching of pre-existing M1 macrophages within the site of injury. The differences between these groups have not been investigated, but have major implications for understanding and treating pathologies characterized by deficient M2 activation, such as chronic wounds, which also exhibit diminished M1 macrophage behavior. This study investigated the influence of prior M1 activation on human macrophage polarization to an M2 phenotype in response to IL-4 treatment in vitro. Compared to unactivated (M0) macrophages, M1 macrophages upregulated several receptors that promote the M2 phenotype, including the primary receptor for IL-4. M1 activation also changed the macrophage response to treatment with IL-4, generating an M2-like phenotype with a distinct gene and protein expression signature compared to M2 macrophages prepared directly from M0 macrophages. Functionally, compared to M0-derived M2 macrophages, M1-derived M2 macrophages demonstrated increased migratory response to SDF-1 $\alpha$, and conditioned media from these macrophages promoted increased recruitment of endothelial cells in transwell assays. Together, these findings indicate the importance of prior M1 activation in regulating subsequent $\mathrm{M} 2$ behavior, and suggest that augmentation of $\mathrm{M} 1$ behavior may be a therapeutic target in dysfunctional tissue repair. 


\section{Introduction}

Macrophages are key players in the tissue repair process that regulate the growth of new blood vessels, or angiogenesis. Due to their highly plastic nature, macrophage phenotype varies with the shifting phases of healing by changing in response to external cues. The early inflammatory response to injury is dominated by a pro-inflammatory population commonly referred to as "M1," which then give way to a very different population known as "M2" in later reparative stages. Studies have shown that this phenotype-switching behavior is characteristic of normal tissue repair, and may be particularly important for angiogenesis (1-3). The late stage, reparative macrophages seen in vivo can emerge in several ways: the recruitment and differentiation of newly arriving non-classical monocytes, the phenotypic switching of pre-existing proinflammatory macrophages, and the proliferation of these populations $(1,4-9)$. It is yet unknown to what extent each mechanism is responsible for generating the collective "M2" population, and it is probable that all are required for normal healing. Nonetheless, studies have shown that when macrophages are depleted in the early inflammatory stage, late-stage M2 macrophages are also reduced and healing is inhibited $(6,10)$. Furthermore, it is known that in several diseases in which healing is stalled, such as in chronic wounds, pro-inflammatory M1-like macrophages are insufficiently activated and also fail to switch to an M2 phenotype (11-16). Thus, M1-to-M2 phenotypic switching is likely a key mechanism in proper healing, and M1 activation may be an important regulator of subsequent M2 polarization. Despite the significance of the M1-to-M2 transition, the effects of $\mathrm{M} 1$ activation on subsequent M2 properties and the specific functions of this M1-derived M2 population have not yet been investigated. 
It is important to note that macrophage phenotypes can be categorized using a number of nomenclatures, none of which are universally employed or accepted. One approach is to describe phenotypes based on function, such as "pro-inflammatory," "pro-angiogenic," "anti-inflammatory," "pro-healing," etc. However, this nomenclature can be problematic due to the influence of timing and context on macrophage behavior; for example, M1 macrophages have been described as both anti- and pro-angiogenic $(17,18)$ and M2 macrophages, which are commonly called anti-inflammatory, propagate type 2 inflammation $(19,20)$. Alternatively, the dichotomous system of classically activated "M1" and alternatively activated "M2" was originally coined in reference to the polarizing cytokines secreted by Th1 and Th2 cells (21). This M1/M2 system has since expanded to recognize distinct M2 subtypes, including "M2a" (IL-4-activated macrophages), and is especially useful for describing macrophages activated in vitro, though it falls short in describing the true complexity of macrophage phenotypes. Macrophages in vivo can rarely be described as entirely M1 or M2, instead existing somewhere on a wide spectrum of polarization, but the expression of previously-defined M1 and M2 markers determined from in vitro studies can help to identify "M1-like" or "M2-like" features of more complex phenotypes. In this study we activated macrophages in vitro using defined chemical stimuli, and will therefore use the "M1" and "M2" terminologies for these experiments. For more extensive reviews of the pros and cons of various macrophage nomenclature systems, see Murray et al. (22) and Spiller and Koh (23).

Many studies have been conducted to elucidate the roles of M1-like and M2-like macrophages during angiogenesis and healing in vivo. In the early stages of healing, 
pro-inflammatory circulating monocytes are recruited to the site of injury where they differentiate to M1-like macrophages $(1,24,25)$. These early-arriving macrophages have been shown to be crucial for wound vascularization and complete healing $(4,10$, 26). After this stage, M2-like macrophages begin to dominate the milieu, further promoting tissue regeneration (10, 27-29). These M2 macrophages are often modeled in vitro via activation with IL-4 (30-34), although other relevant M2-promoting stimuli include IL10 and apoptotic cells $(18,35)$. Although the specific roles of each phenotype are still being investigated, the current literature suggests that multiple phenotypes work together in a complementary manner to orchestrate normal healing. Indeed, drug delivery systems designed to sequentially release M1-promoting followed by M2promoting signals have shown promise in promoting angiogenesis and healing (36).

We hypothesized that M1-to-M2 switching generates a unique phenotype that is important for late-stage healing. We first investigated the potential for unactivated (M0) and M1 macrophages to switch to the M2 phenotype in response to IL-4 in vitro. Then, to understand the impact of M1 activation on subsequent M2 behavior, we compared the gene expression profiles of IL-4-induced M2 macrophages derived from M0 or M1 macrophages (called $\mathrm{M} 0 \rightarrow \mathrm{M} 2$ and $\mathrm{M} 1 \rightarrow \mathrm{M} 2$ ), then conducted several functional assays of macrophage behavior. The results identify $\mathrm{M} 1 \rightarrow \mathrm{M} 2$ macrophages as a distinct phenotype that upregulates select M2 markers and several genes and proteins related to angiogenesis, and exhibits enhanced pro-healing functions. 


\section{Materials and methods}

\section{Monocyte culture and differentiation into polarized macrophages}

Primary human monocytes were purchased from the University of Pennsylvania Human Immunology Core, or isolated as previously described $(37,38)$ from peripheral blood purchased from the New York Blood Center. Monocytes were cultured on ultralow attachment plates in RPMI-1640 supplemented with $10 \%$ human serum and $1 \%$ penicillin/streptomycin. Media was additionally supplemented with $20 \mathrm{ng} / \mathrm{mL}$ of MCSF (Peprotech, Rocky Hill, NJ, U.S.) to induce differentiation into macrophages. On day 5, macrophages were either maintained in an unactivated M0 state or they were M1activated with $100 \mathrm{ng} / \mathrm{mL}$ of IFNg (Peprotech) and $100 \mathrm{ng} / \mathrm{mL}$ of LPS (MilliporeSigma, Burlington, MA, U.S.) for 24-48 hours (Figure 1A). For IL-4Ra flow cytometry, an additional M2 group, activated with $40 \mathrm{ng} / \mathrm{mL}$ of IL-4 (Peprotech) and $20 \mathrm{ng} / \mathrm{mL}$ of IL-13 (Peprotech) was included. For dose response experiments, M0 and M1 macrophages were treated with four doses of IL-4 (10 ng/mL, $1 \mathrm{ng} / \mathrm{mL}, 0.1 \mathrm{ng} / \mathrm{mL}$, and $0.01 \mathrm{ng} / \mathrm{mL})$ for six hours. To induce the $\mathrm{M} 0 \rightarrow \mathrm{M} 2$ and $\mathrm{M} 1 \rightarrow \mathrm{M} 2$ phenotypes, $\mathrm{M} 0$ and $\mathrm{M} 1$ macrophages were treated with $10 \mathrm{ng} / \mathrm{mL}$ of IL-4 (Peprotech) on day 6 , respectively, for an additional 24-72 hours.

\section{NanoString gene expression assay}

RNA was extracted from cells using the RNAqueous-Micro Total RNA Isolation Kit (ThermoFisher, Waltham, MA, U.S.) and RNA concentration was measured using the Nanodrop ND1000. Gene expression was measured with a custom-designed 72gene panel (Supplemental Table 1) representing genes associated with typical M1 and M2 phenotype markers as well as angiogenesis and fibrosis (NanoString Technologies, 
Seattle, WA, U.S.), using 100 ng of RNA per sample, according to NanoString's protocol. Quality control analysis was conducted and raw data were normalized to inhouse positive controls using nSolver 4.0 software (NanoString Technologies, Seattle, WA, U.S.) as recommended by the manufacturer.

\section{Flow cytometry}

Macrophages were incubated with Fc block (BD Biosciences, Franklin Lakes, NJ, U.S.) for 10 minutes at $4^{\circ} \mathrm{C}$, then incubated with primary-conjugated antibodies (Biolegend, San Diego, CA, U.S.) and viability stain (Invitrogen, Carlsbad, CA, U.S.) for 15 minutes at $4^{\circ} \mathrm{C}$. Antibodies used to stain for IL-4Ra were APC anti-human CD124 (IL-4Ra) (Biolegend, clone G077F6, 1:100) and Live/Dead Fixable Green (Invitrogen, 1:200). To amplify IL-4Ra signal, APC FASER kit (Miltenyi Biotec, Bergisch Gladbach, Germany) was used for two cycles, according to kit instructions. Viability stain used to stain macrophages for phagocytosis was Live/Dead Fixable Aqua (Invitrogen, 1:200). Samples were fixed and permeabilized using the Foxp3/Transcription Factor Staining Buffer Kit (Tonbo Biosciences, San Diego, CA, U.S.), then incubated with primaryconjugated antibodies for 45 minutes at $4^{\circ} \mathrm{C}$. PE anti-human CD68 (Biolegend, clone $\mathrm{Y} 1 / 82 \mathrm{~A}, 1: 100)$ was used to stain macrophages for phagocytosis. Data was measured on the Accuri C6 (BD) or LSR II (BD) flow cytometer and analyzed using FlowJo v10 software (BD).

\section{Quantitative reverse transcription polymerase chain reaction}

RNA was extracted using the RNAqueous-Micro Total RNA Isolation Kit and RNA concentration was measured using the Tecan Infinite M200 microplate reader. cDNA was synthesized using the High-Capacity cDNA Reverse Transcription Kit 
(Invitrogen). qRT-PCR was conducted using custom oligonucleotides (ThermoFisher,

Supplemental Table 2) and SYBR Green Master Mix (ThermoFisher). Statistical testing was performed using log-transformed data.

\section{Enzyme-linked immunosorbent assays (ELISAs)}

Cell-conditioned media was collected 24 hours after the addition of polarizing cytokines and frozen at $-80^{\circ} \mathrm{C}$ until ELISAs were run. ELISAs were conducted using kits from Peprotech (PDGF-BB, CCL5, and VEGFA) and R\&D Systems (Minneapolis, MN, U.S.) (CCL17). Absorbance was measured on the Tecan Infinite M200 microplate reader.

\section{Migration assays}

Macrophage migration in response to SDF-1a

$6.5 \mathrm{~mm}$ polyester transwell membranes with $8.0 \mu \mathrm{m}$ pores (Corning, Corning, NY, U.S.) were coated with $5 \mu \mathrm{g} / \mathrm{cm}^{2}$ of bovine type I collagen (Gibco, ThermoFisher) for one hour and placed in a 24-well plate. Macrophages were suspended in serum-free media at a concentration of 500,000 cells $/ \mathrm{mL}$ and $100 \mu \mathrm{L}$ were added to each transwell. After allowing cells to settle for 10 minutes, $600 \mu \mathrm{L}$ of media supplemented with 10 $\mathrm{ng} / \mathrm{mL}$ of recombinant human stromal derived factor- $1 \alpha$ (SDF-1 $1 \alpha$ ) was added to the bottom chambers of the experimental group. $600 \mu \mathrm{L}$ of basal media was added to the bottom chambers of the negative control group. Samples were incubated for 24 hours, after which media and remaining cells in the upper chamber were removed with sterile cotton swabs, while cells adhered to the lower membrane were fixed with ethanol and stained with $0.2 \%$ crystal violet solution (Fisher Chemical, Hampton, $\mathrm{NH}$, U.S.). Images 
of the transwells were taken on an inverted microscope set to 10x objective and cells were counted using ImageJ software (NIH, Bethesda, MD, U.S.).

Endothelial cell migration in response to macrophage-conditioned media

Macrophage-conditioned media without the influence of polarizing cytokines was generated by incubating polarized macrophages in basal media for 24 hours, then frozen at $-80^{\circ} \mathrm{C}$ until assay was conducted. Human umbilical vein endothelial cells (HUVECs) were suspended in serum-free media at a concentration of $500,000 \mathrm{cells} / \mathrm{mL}$ and $100 \mu \mathrm{L}$ were added to each transwell. After allowing cells to settle for 10 minutes, $600 \mu \mathrm{L}$ of macrophage-conditioned media was added to the bottom chambers. Samples were incubated for 24 hours, after which cells on the bottom of the transwell were stained and counted as described above.

\section{MTT metabolism assay}

HUVECs were seeded in 96-well plates at 50,000 cells/well and cultured in 100 $\mu \mathrm{L}$ of macrophage-conditioned media for 24-48 hours. Media supplemented with 10 $\mathrm{ng} / \mathrm{mL}$ of recombinant human VEGF (GenScript, Piscataway, NJ, U.S.) was used as a positive control. $10 \mu \mathrm{L}$ of MTT reagent from the MTT Cell Proliferation Assay Kit (Cayman Chemical, Ann Arbor, MI, U.S.) was added to each well of one plate and incubated for 4 hours. $100 \mu \mathrm{L}$ of sodium dodecyl sulfate from the same kit was then added to each well and incubated for an additional 18 hours. Absorbance at $570 \mathrm{~nm}$ was measured on the Tecan Infinite M200 microplate reader.

\section{Phagocytosis}


Viable HL-60 cells were labelled with CellTrace Far Red (Invitrogen) according to manufacturer instructions, then serum-starved for 2 hours. Hydrogen peroxide (Fisher Chemical) was added to the cell suspension at a concentration of $800 \mu \mathrm{M}$ for 3 hours to induce apoptosis. Macrophages were co-cultured with either apoptotic HL-60s or crimson FluoSpheres (Invitrogen) for 3 hours to facilitate phagocytosis. Samples were immediately stained for CD68 and Live/Dead for flow cytometry analysis as described above.

\section{Statistics}

Most results were analyzed using GraphPad Prism 8 software (GraphPad Software, San Diego, CA, U.S.). Heat map and dendrogram were generated using R software. 


\section{$\underline{\text { Results }}$}

M1 activation increases expression of IL-4Ra, IL4 signaling genes, and other M2promoting receptors

In order to test the potential of M0 and M1 macrophages to switch to the M2 phenotype, we determined their expression of receptors known to promote the M2 phenotype. As IL-4 is the primary cytokine used to polarize M2 macrophages in vitro to model macrophages in late-stage tissue repair, we used NanoString multiplex gene expression analysis to measure the expression of the three components of the IL-4 receptor complexes (IL4R, IL13RA1, IL2RG) as well as their corresponding Janus kinases (JAK1, JAK2, JAK3) and several other genes involved in IL-4 signaling (39). Expression of the receptor complexes, Janus kinases, and other IL-4 signaling genes was significantly upregulated in M1 macrophages compared to M0 macrophages (Figure 1B). We then verified surface expression of IL-4 receptor alpha (IL-4Ra) on M1 macrophages via flow cytometry. Mean fluorescence intensity (MFI) of IL-4Ra was significantly higher on $\mathrm{M} 1$ macrophages than both $\mathrm{M} 0$ and $\mathrm{M} 2$ macrophages, as was the percentage of IL-4Ra-positive cells (Figure 1C).

In order to determine if this upregulation of M2-promoting genes and proteins is exclusive to the IL-4 pathway, we used qRT-PCR to measure gene expression of an additional repertoire of receptors involved in M2 polarization outside of the IL-4 pathway, including AXL, MERTK, CMKLR1, IL10RB, TLR2, TNFR2, and NR3C1 (31, 40-44). All receptors except MERTK and NR3C1 were upregulated in M1 macrophages compared to M0 (Figure 1D). Together, these data indicate that M1 macrophages may 
be primed to switch to the M2 phenotype via upregulation of M2-promoting receptors, particularly IL-4Ra.

M1 macrophages are not more sensitive to IL-4 than MO macrophages

Having confirmed upregulation of IL-4Ra in M1 macrophages, we hypothesized that this increased expression would translate to increased sensitivity to IL-4. To test this hypothesis, we first compared the response of $\mathrm{M} 0$ and $\mathrm{M} 1$ macrophages to low doses of the cytokine. After 6 hours of exposure to varying doses $(10,1,0.1$, and 0.01 $\mathrm{ng} / \mathrm{mL}$ ), we used NanoString to measure the expression of a panel of genes including M1 markers, IL-4 signaling genes, and the M2 markers CCL22 and CD206. We expected the M1 macrophages to upregulate M2 genes at lower doses compared to the M0 group. In contrast, IL-4-treated M0 macrophages exhibited higher CCL22 expression at the $10 \mathrm{ng} / \mathrm{mL}$ dose and higher CD206 expression at doses as low as 0.1 $\mathrm{ng} / \mathrm{mL}$ (Figure 2B). We then tested whether M1 macrophages would upregulate M2 genes more rapidly than M0 macrophages after IL-4 treatment. Using the same gene panel with an additional M2 marker, CCL17, we treated M0 and M1 macrophages with $10 \mathrm{ng} / \mathrm{mL}$ of IL-4 and tracked the expression of these genes over the course of 24 hours, expecting M1 macrophages to upregulate M2 marker genes at earlier time points. Instead, we found that the two groups upregulated different M2 markers within 24 hours of IL-4 exposure. While IL-4-treated M0 macrophages exhibited increased expression of CD206 and CCL22 immediately after stimulation, IL-4-treated M1 macrophages upregulated CCL17, which increased for the duration of the study (Figure 2C). Additionally, M1 genes were downregulated in IL-4-treated M1 macrophages within 
24 hours, confirming a switch in phenotype (Figure 2D). All but two of the fourteen IL-4 signaling genes evaluated were expressed at higher levels by M1-derived M2

macrophages for the 24 hour period, although they generally decreased during this time frame (Figure 2E). Therefore, the increased expression of M2-promoting receptors did not lead to a more sensitive or faster response to IL-4 treatment, but IL-4 treatment did cause upregulation of different M2 markers in M1 macrophages compared to M0.

M0-derived and M1-derived M2 macrophages are distinct phenotypes

These unexpected results led to a new hypothesis that M1 activation changes the subsequent response to IL-4, as measured by differences in expression of M2 markers and possibly other genes. Using an expanded NanoString panel of genes including macrophage phenotype markers, genes associated with angiogenesis, and genes associated with tissue deposition or fibrosis, we evaluated the gene expression profiles of M0 and M1 macrophages treated with $10 \mathrm{ng} / \mathrm{mL}$ IL-4 for 24 hours $(\mathrm{M} 0 \rightarrow \mathrm{M} 2$ vs. $\mathrm{M} 1 \rightarrow \mathrm{M} 2$, respectively). M1 $\rightarrow \mathrm{M} 2$ macrophages expressed higher levels of several genes compared to $\mathrm{M} 0, \mathrm{M} 1$, and $\mathrm{M} 0 \rightarrow \mathrm{M} 2$ macrophages, including CCL17, CCL5, CXCR4, JAG1, VEGFA, and PDGFB (Figure 3A). M0 $\rightarrow \mathrm{M} 2$ macrophages, on the other hand, expressed higher levels of CD206, DACT1, and HSPG2. Both the M0 $\rightarrow$ M2 and M1 $\rightarrow$ M2 groups upregulated CCL22 and FLT1 (VEGF receptor-1) compared to the M0 and M1 controls, but were not significantly different from each other. Hierarchical clustering of the entire 72-gene panel data set established that the $\mathrm{M} 1 \rightarrow \mathrm{M} 2$ group, while more closely related to the $\mathrm{M} 0 \rightarrow \mathrm{M} 2$ group than to the $\mathrm{M} 0$ or $\mathrm{M} 1$ controls, 
clustered separately from the M0-M2 group and is therefore phenotypically distinct (Figure 3B).

In order to determine whether increased gene expression of CCL17, CCL5, VEGFA, and PDGF-BB translated to increased protein secretion, we conducted ELISAs to measure concentration of these proteins in the culture media after polarization. As expected, M1 $\rightarrow$ M2 macrophages secreted higher levels of CCL17, CCL5, and PDGF$\mathrm{BB}$ compared to $\mathrm{M0} \rightarrow \mathrm{M} 2$ (Figure $3 \mathrm{C}$ ). Results of the VEGFA ELISAs, on the other hand, exhibited high variability and no significant differences were found (Supplemental Figure 1).

Collectively, these results indicate that M2 macrophages that were previously M0 or M1 exhibit distinct phenotypes.

$M 0 \rightarrow M 2$ and $M 1 \rightarrow M 2$ macrophages exhibit distinct functions

Finally, we set out to evaluate potential differences in functional behavior between $\mathrm{M} 1 \rightarrow \mathrm{M} 2$ and $\mathrm{M} 0 \rightarrow \mathrm{M} 2$ macrophages. Because a critical process in the early inflammatory response is the recruitment of macrophages to injured cells in large part through SDF-1 1 , and because $\mathrm{M} 1 \rightarrow \mathrm{M} 2$ macrophages upregulated expression of $\mathrm{CXCR} 4$, the SDF-1a ligand, compared to $\mathrm{M} 0 \rightarrow \mathrm{M} 2$ macrophages, we first tested the ability of these cells to migrate in response to SDF-1a. Using a transwell migration assay, we measured the migratory response of macrophages to basal media or to media containing SDF-1 $\mathrm{a} . \mathrm{M} 0 \rightarrow \mathrm{M} 2$ macrophages were more motile than $\mathrm{M} 1 \rightarrow \mathrm{M} 2$ macrophages, migrating more in basal media (Figure 4A). However, the inclusion of 
SDF-1 $\alpha$ in the media increased transwell migration of $M 1 \rightarrow M 2$ macrophages, while it had no effect on $\mathrm{M} 0 \rightarrow \mathrm{M} 2$ macrophages (Figure 4B).

Again using a transwell migration assay, we next found that conditioned media from $\mathrm{M} 1 \rightarrow \mathrm{M} 2$ macrophages recruited more HUVECs compared to $\mathrm{M} 0 \rightarrow \mathrm{M} 2$ macrophage-conditioned media (Figure 4C). We also measured proliferation of HUVECs over 24 and 48 hours of incubation in macrophage-conditioned media, but no significant differences were observed between the HUVECs incubated in media from $\mathrm{M} 0 \rightarrow \mathrm{M} 2$ or $\mathrm{M} 1 \rightarrow \mathrm{M} 2$ macrophages (Supplemental Figure 2).

Macrophages are well-known for their role as phagocytes, and some studies have shown increased phagocytosis among M2-activated macrophages $(45,46)$. In order to assess differences in phagocytic activity between $\mathrm{M} 0 \rightarrow \mathrm{M} 2$ and $\mathrm{M} 1 \rightarrow \mathrm{M} 2$ macrophages, we cultured each group for 3 hours with either fluorescently labelled latex beads or apoptotic HL-60 cells. Using flow cytometry to identify target-containing macrophages, we found no significant differences between the groups in percentage of target-positive cells or MFI of target (Supplemental Figure 3).

\section{Discussion}

We have established here that M1 activation primes macrophages to polarize to an M2-like phenotype that exhibits unique gene and protein signatures compared to M2 macrophages derived from an unactivated state. $\mathrm{M} 1 \rightarrow \mathrm{M} 2$ macrophages were more migratory towards SDF-1 $\alpha$, suggesting an enhanced ability to traffic towards sites of injury, and induced more HUVEC migration than did $\mathrm{M} 0 \rightarrow \mathrm{M} 2$ macrophages, suggesting 
that they may play an important role in angiogenesis. The characterization of this unique phenotype points to M1 activation as a major influence on subsequent M2 macrophage behavior. These results have critical implications for understanding how macrophage phenotype is regulated during tissue repair, and suggest that correcting M1 activation may be a therapeutic target for impaired healing situations characterized by deficient M2 activation.

Several studies have previously established a role for M1 macrophages in early angiogenesis $(3,4,10)$, and further investigations have suggested that they may also serve to regulate $\mathrm{M} 2$ polarization in late-stage healing. For example, M1 macrophages not only have the capacity to switch to the M2 phenotype $(1,5,6,8,9)$, but stimulation of M1 activity has also been shown to improve subsequent M2 marker expression (4749). Likewise, studies in which M1 macrophages were inhibited during early stages of healing resulted in diminished $\mathrm{M} 2$ polarization later on $(6,10)$. Correspondent to these findings, several pathologies in which the M2 response is inhibited, such as diabetic wounds, also initially lack robust M1 activity at early stages (11-16). Exactly how M1 activation influences M2 behavior, though, remains poorly understood. M2-like macrophages that were previously pro-inflammatory and those that were derived from an unactivated state are both present in the site of injury during the later stages of healing (8). Our findings shed light on the M1-to-M2 transition by showing that M0 $\rightarrow \mathrm{M} 2$ and $\mathrm{M} 1 \rightarrow \mathrm{M} 2$ macrophages are different phenotypes, and perhaps perform distinct yet complementary functions in vivo.

Surprisingly, although M1 macrophages upregulated M2-promoting receptors, they did not exhibit increased responsiveness to IL-4 in terms of sensitivity to lower 
doses or more rapid responses. Rather, M1 activation seems to change the response to IL-4 by generating a distinct M2-like phenotype with a unique gene signature and set of behaviors. This altered response may stem from a change in the IL-4 signaling pathway upon M1 activation - for example, STAT6 is more highly expressed in M1 macrophages compared to M0 macrophages, while M0 macrophages exhibit higher expression of PPARy (Figure 1B). Deeper investigation into IL-4 pathway changes may be required to understand the underlying mechanisms of the M1 macrophage response to IL-4.

This study establishes an initial characterization of $\mathrm{M} 1 \rightarrow \mathrm{M} 2$ macrophages, and shows they are phenotypically distinct from $\mathrm{M} 0 \rightarrow \mathrm{M} 2$ macrophages. In line with their emergence during the later stages of tissue repair and angiogenesis, $M 1 \rightarrow M 2$ macrophages upregulate PDGF-BB, essential for the stabilization of nascent vasculature, and CCL17, which may promote the resolution of inflammation via regulatory $\mathrm{T}$ cell recruitment. Though promising, these findings must be investigated further, potentially via transcriptome sequencing to identify all differences between $\mathrm{M} 0 \rightarrow \mathrm{M} 2$ and $\mathrm{M} 1 \rightarrow \mathrm{M} 2$ macrophages, as well as studies to confirm this phenomenon in vivo.

In order to design therapies that promote angiogenesis and healing via macrophage modulation, a thorough understanding of regulatory mechanisms during normal tissue repair is critical. Although the effects of $\mathrm{M} 1$ activation on $\mathrm{M} 2$ polarization were previously unknown, we have shown here that the $\mathrm{M} 1 \rightarrow \mathrm{M} 2$ phenotype is distinct and appears to display important functions for wound healing and angiogenesis. 


\section{Acknowledgements}

We thank Jessica Eager for technical assistance with heat map generation and hierarchical clustering data analysis. This study was supported by research funding from NHLBI (grant number R01 HL130037).

\section{Authorship Contributions}

E.M.O. performed the experiments and analyzed results; E.M.O. and K.L.S. designed the research and wrote the paper; K.L.S. supervised the research.

\section{Disclosure of Conflicts of Interest}

The authors declare no conflicts of interest.

\section{$\underline{\text { References }}$}

1. Arnold L, Henry A, Poron F, Baba-Amer Y, van Rooijen N, Plonquet A, et al. Inflammatory monocytes recruited after skeletal muscle injury switch into antiinflammatory macrophages to support myogenesis. Journal of Experimental Medicine. 2007;204(5):1057.

2. Troidl C JG, Troidl K, Hoffmann J, Mollmann H, Nef H, Schaper W, Hamm CW, SchmitzRixen T. The Temporal and Spatial Distribution of Macrophage Subpopulations During Arteriogenesis. Current Vascular Pharmacology. 2013;11(1):5-12.

3. Spiller KL, Anfang RR, Spiller KJ, Ng J, Nakazawa KR, Daulton JW, et al. The role of macrophage phenotype in vascularization of tissue engineering scaffolds. Biomaterials. 2014;35(15):4477-88.

4. Gurevich DB, Severn CE, Twomey C, Greenhough A, Cash J, Toye AM, et al. Live imaging of wound angiogenesis reveals macrophage orchestrated vessel sprouting and regression. The EMBO Journal. 2018;37(11).

5. Bencze M, Negroni E, Vallese D, Yacoub-Youssef $H$, Chaouch S, Wolff A, et al. Proinflammatory Macrophages Enhance the Regenerative Capacity of Human Myoblasts by Modifying Their Kinetics of Proliferation and Differentiation. Molecular Therapy. 2012;20(11):2168-79. 
6. Dal-Secco D, Wang J, Zeng Z, Kolaczkowska E, Wong CHY, Petri B, et al. A dynamic spectrum of monocytes arising from the in situ reprogramming of CCR2+ monocytes at a site of sterile injury. Journal of Experimental Medicine. 2015;212(4):447-56.

7. Jenkins SJ, Ruckerl D, Cook PC, Jones LH, Finkelman FD, van Rooijen N, et al. Local Macrophage Proliferation, Rather than Recruitment from the Blood, Is a Signature of TH2 Inflammation. Science. 2011;332(6035):1284-8.

8. Varga T, Mounier R, Horvath A, Cuvellier S, Dumont F, Poliska S, et al. Highly Dynamic Transcriptional Signature of Distinct Macrophage Subsets during Sterile Inflammation, Resolution, and Tissue Repair. The Journal of Immunology. 2016;196(11):4771-82.

9. Patsalos A, Pap A, Varga T, Trencsenyi G, Contreras GA, Garai I, et al. In situ macrophage phenotypic transition is affected by altered cellular composition prior to acute sterile muscle injury. The Journal of Physiology. 2017;595(17):5815-42.

10. Lucas T, Waisman A, Ranjan R, Roes J, Krieg T, Muller W, et al. Differential Roles of Macrophages in Diverse Phases of Skin Repair. The Journal of Immunology. 2010;184(7):3964-77.

11. Sun C, Sun L, Ma H, Peng J, Zhen Y, Duan K, et al. The phenotype and functional alterations of macrophages in mice with hyperglycemia for long term. Journal of Cellular Physiology. 2011;227(4).

12. Pradhan L, Cai X, Wu S, Andersen ND, Martin M, Malek J, et al. Gene Expression of ProInflammatory Cytokines and Neuropeptides in Diabetic Wound Healing. Journal of Surgical Research. 2011;167(2):336-42.

13. Yuan R, Geng S, Chen K, Diao N, Chu HW, and Li L. Low-grade inflammatory polarization of monocytes impairs wound healing. The Journal of Pathology. 2015;238(4).

14. Yoon P, Keylock KT, Hartman ME, Freund GG, and Woods JA. Macrophage hyporesponsiveness to interferon- $\gamma$ in aged mice is associated with impaired signaling through Jak-STAT. Mechanisms of Ageing and Development. 2004;125(2):137-43.

15. Wilkinson HN, Roberts ER, Stafford AR, Banyard KL, Matteucci P, Mace KA, et al. Tissue Iron Promotes Wound Repair via M2 Macrophage Polarization and the Chemokine (C-C Motif) Ligands 17 and 22. The American Journal of Pathology. 2019;189(11):2196-208.

16. Khanna S, Biswas S, Shang Y, Collard E, Azad A, Kauh C, et al. Macrophage Dysfunction Impairs Resolution of Inflammation in the Wounds of Diabetic Mice. PLOS One. 2010;5(3).

17. Jetten N, Verbruggen S, Gijbels MJ, Post MJ, De Winther MPJ, and Donners MMPC. Antiinflammatory M2, but not pro-inflammatory M1 macrophages promote angiogenesis in vivo. Angiogenesis. 2014;17(1):109-18.

18. Graney PL, Ben-Shaul S, Landau S, Bajpai A, Singh B, Eager J, et al. Macrophages of diverse phenotypes drive vascularization of engineered tissues. Science Advances. 2020;6(18).

19. Siracusa MC, Reece JJ, Urban JF, and Scott AL. Dynamics of lung macrophage activation in response to helminth infection. Journal of Leukocyte Biology. 2008;84(6).

20. Anthony RM, Urban JF, Alem F, Hamed HA, Rozo CT, Boucher JL, et al. Memory TH2 cells induce alternatively activated macrophages to mediate protection against nematode parasites. Nature Medicine. 2006;12:955-60.

21. Stein M, Keshav S, Harris N, and Gordon S. Interleukin 4 potently enhances murine macrophage mannose receptor activity: a marker of alternative immunologic macrophage activation. Journal of Experimental Medicine. 1992;176(1):287.

22. Murray PJ, Allen JE, Biswas SK, Fisher EA, Gilroy DW, Goerdt S, et al. Macrophage Activation and Polarization: Nomenclature and Experimental Guidelines. Immunity. 2014;41(1):14-20.

23. Spiller KL, and Koh TJ. Macrophage-based therapeutic strategies in regenerative medicine. Advanced Drug Delivery Reviews. 2017;122:74-83. 
24. Geissmann F, Manz MG, Jung S, Sieweke MH, Merad M, and Ley K. Development of Monocytes, Macrophages, and Dendritic Cells. Science. 2010;327(5966):656-61.

25. Swirski FK, Nahrendorf M, Etzrodt M, Wildgruber M, Cortez-Retamozo V, Panizzi P, et al. Identification of Splenic Reservoir Monocytes and Their Deployment to Inflammatory Sites. Science. 2009;325(5940):612-6.

26. Cai J, Feng J, Liu K, Zhou S, and Lu F. Early Macrophage Infiltration Improves Fat Graft Survival by Inducing Angiogenesis and Hematopoietic Stem Cell Recruitment. Plastic and Reconstructive Surgery. 2018;141(2):376-86.

27. Mirza R, and Koh TJ. Dysregulation of monocyte/macrophage phenotype in wounds of diabetic mice. Cytokine. 2011;56(2):256-64.

28. Saclier M, Yacoub-Youssef H, Mackey AL, Arnold L, Ardjoune H, Magnan M, et al. Differentially Activated Macrophages Orchestrate Myogenic Precursor Cell Fate During Human Skeletal Muscle Regeneration. Stem Cells. 2013;31(2):384-96.

29. Perdiguero E, Sousa-Victor P, Ruiz-Bonilla V, Jardi M, Caelles C, Serrano AL, et al. p38/MKP-1-regulated AKT coordinates macrophage transitions and resolution of inflammation during tissue repair. Journal of Cell Biology. 2011;195(2):307-22.

30. Liu X, Liu J, Zhao S, Zhang H, Cai W, Cai M, et al. Interleukin-4 Is Essential for Microglia/Macrophage M2 Polarization and Long-Term Recovery After Cerebral Ischemia. Stroke. 2016;47:498-504.

31. Bosurgi L, Cao YG, Cabeza-Cabrerizo M, Tucci A, Hughes LD, Kong Y, et al. Macrophage function in tissue repair and remodeling requires IL-4 or IL-13 with apoptotic cells. Science. 2017;356(6342):1072-6.

32. Balce DR, Li B, Allan ERO, Rybicka JM, Krohn RM, and Yates RM. Alternative activation of macrophages by IL-4 enhances the proteolytic capacity of their phagosomes through synergistic mechanisms. Blood. 2011;118(15):4199-208.

33. Salmon-Ehr V, Ramont L, Godeau G, Birembaut P, Guenounou M, Bernard P, et al. Implication of Interleukin-4 in Wound Healing. Laboratory Investigation. 2000;80:1337-43.

34. Francos-Quijorna I A-AJ, Martinez-Muriana A, Lopez-Vales R. IL-4 drives microglia and macrophages toward a phenotype conducive for tissue repair and functional recovery after spinal cord injury. Glia. 2016;64(12):2079-92.

35. Lurier EB, Dalton D, Dampier W, Raman P, Nassiri S, Ferraro NM, et al. Transcriptome analysis of $\mathrm{IL}-10$-stimulated (M2c) macrophages by next-generation sequencing. Immunobiology. 2017;222(7):847-56.

36. O'Brien EM, Risser GE, and Spiller KL. Sequential drug delivery to modulate macrophage behavior and enhance implant integration. Advanced Drug Delivery Reviews. 2019;149150:85-94.

37. Danciger JS, Lutz M, Hama S, Cruz D, Castrillo A, Lazaro J, et al. Method for large scale isolation, culture and cryopreservation of human monocytes suitable for chemotaxis, cellular adhesion assays, macrophage and dendritic cell differentiation. Journal of Immunological Methods. 2004;288(1-2):123-34.

38. Spiller KL, Nassiri S, Witherel CE, Anfang RR, $\mathrm{Ng} J$, Nakazawa KR, et al. Sequential delivery of immunomodulatory cytokines to facilitate the M1-to-M2 transition of macrophages and enhance vascularization of bone scaffolds. Biomaterials. 2015;37:194207.

39. McCormick SM, and Heller NM. Commentary: IL-4 and IL-13 receptors and signaling. Cytokine. 2015;75(1):38-50.

40. Mariani F, and Roncucci L. Chemerin/chemR23 axis in inflammation onset and resolution. Inflammation Research. 2015;64(2):85-95.

41. Spencer SD, Di Marco F, Hooley J, Pitts-Meek S, Bauer M, Ryan AM, et al. The Orphan Receptor CRF2-4 Is an Essential Subunit of the Interleukin 10 Receptor. Journal of Experimental Medicine. 1998;187(4):571-8. 
42. Yang HZ, Cui B, Liu HZ, Chen ZR, Yan HM, Hua F, et al. Targeting TLR2 Attenuates Pulmonary Inflammation and Fibrosis by Reversion of Suppressive Immune Microenvironment. The Journal of Immunology. 2009;182(1):692-702.

43. Candel S, de Oliveira S, Lopez-Munoz A, Garcia-Moreno D, Espin-Palazon R, and Tyrkalska SD. Tnfa signaling through Tnfr2 protects skin against oxidative stress-induced inflammation. PLoS Biology. 2014;12(5).

44. Glass CK, and Saijo K. Nuclear receptor transrepression pathways that regulate inflammation in macrophages and T cells. Nature Reviews Immunology. 2010;10:365-76.

45. Tarique AA, Logan J, Thomas E, Holt PG, Sly PD, and Fantino E. Phenotypic, Functional, and Plasticity Features of Classical and Alternatively Activated Human Macrophages. American Journal of Respiratory Cell and Molecular Biology. 2015;53(5):676-88.

46. Gratchev A, Kzhyshkowska J, Utikal J, and Goerdt S. Interleukin-4 and Dexamethasone Counterregulate Extracellular Matrix Remodelling and Phagocytosis in Type-2 Macrophages. Scandinavian Journal of Immunology. 2005;61(1):10-7.

47. Rao AJ, Gibon E, Ma T, Yao Z, Smith RL, and Goodman SB. Revision joint replacement, wear particles, and macrophage polarization. Acta Biomaterialia. 2012;8(7):2815-23.

48. Leal EC, Carvalho E, Tellechea A, Kafanas A, Tecilazich F, Kearney C, et al. Substance $P$ Promotes Wound Healing in Diabetes by Modulating Inflammation and Macrophage Phenotype. The American Journal of Pathology. 2015;185(6):1638-48.

49. Rybalko V, Hsieh PL, Merscham-Banda M, Suggs LJ, and Farrar RP. The Development of Macrophage-Mediated Cell Therapy to Improve Skeletal Muscle Function after Injury. PLOS One. 2015.

\section{Figure Legends}

Figure 1. M0 and M1 macrophage expression of M2-promoting receptors. (A)

Polarization of unactivated (M0) macrophages to M1 or M2. (B) NanoString counts of genes associated with the IL-4 signaling pathway, using cells collected 24 hours after the addition of polarizing cytokines (day 6 ). Data are represented as mean \pm SD.

Unpaired t-test, $n=4$ donors, ${ }^{*} p<0.05,{ }^{* *} p<0.01,{ }^{* * *} p<0.001$. (C) Flow cytometric analysis of IL-4Ra expression, using cells collected at day 7. Data are represented as mean \pm SD. One way ANOVA with Tukey's post-hoc, $n=4$ donors, ${ }^{* *} p<0.01$. (D) $q R T-$ PCR analysis of receptors associated with promoting an M2-like macrophage phenotype, using cells collected at day 7 . Data are represented as mean \pm SD. Unpaired t-test, $n=3-4$ donors, ${ }^{*} p<0.05,{ }^{* *} p<0.01,{ }^{* * * *} p<0.0001$. 
Figure 2. Response of M0 and M1 macrophages to IL-4. (A) Treatment of M0 or M1 macrophages with IL4 to generate M0-derived M2 (M0-M2) or M1-derived M2 (M1-M2). (B) NanoString counts of M2 genes after 6 hours of exposure to varying doses of IL-4. Data are represented as mean \pm SD. 2-way ANOVA with Sidak's test, $n=4$ donors, ${ }^{*} p<0.05,{ }^{* * *} p<0.0001$. (C) Nanostring counts of genes associated with M2 phenotype, (D) M1 phenotype, and (E) IL-4 signaling pathway over the course of 24 hours of exposure to $10 \mathrm{ng} / \mathrm{mL}$ of IL-4. Data are represented as mean only, $\mathrm{n}=4$ donors.

Figure 3. Differential gene expression in $M 1 \rightarrow M 2$ macrophages. (A) NanoString gene counts of highly expressed markers associated with M2 phenotype, angiogenesis, and fibrosis. Data are represented as mean \pm SD. One-way ANOVA with Tukey's posthoc, $n=7$ donors, ${ }^{*} p<0.05,{ }^{* *} p<0.01,{ }^{* * *} p<0.001,{ }^{* * *} p<0.0001$. (B) Hierarchical clustering of entire data set. (C) Protein secretion of selected highly-expressed M1 $\rightarrow \mathrm{M} 2$ genes. ELISA analysis of macrophage-conditioned media. Data are represented as mean \pm SD. One-way ANOVA with Tukey's post-hoc, $n=3-4$ donors, ${ }^{* * *} \mathrm{p}<0.001$. Only significant differences between M0-M2 and M1-M2 are depicted, although differences were detected between other groups.

Figure 4. Functional assays in $M 0 \rightarrow M 2$ and $M 1 \rightarrow M 2$ macrophages. (A) Migratory response of $\mathrm{M} 0 \rightarrow \mathrm{M} 2$ and $\mathrm{M} 1 \rightarrow \mathrm{M} 2$ macrophages towards media \pm SDF-1. Data are represented as single replicates with mean only. One-way ANOVA with Tukey's posthoc, $n=6$ replicates from 3 donors depicted with different symbols, ${ }^{*} p<0.05$. (B) Migratory response of macrophages towards SDF-1, shown as fold change of experimental cell counts over blank negative control cell counts. Data are represented as mean $\pm S D$. Unpaired t-test conducted on log-transformed data, $n=6$ replicates from 
bioRxiv preprint doi: https://doi.org/10.1101/2021.04.06.438673; this version posted April 8, 2021. The copyright holder for this preprint (which was not certified by peer review) is the author/funder, who has granted bioRxiv a license to display the preprint in perpetuity. It is made available under aCC-BY-NC-ND 4.0 International license.

$\mathrm{n}=3$ donors, ${ }^{* *} \mathrm{p}<0.001$. (B) Endothelial cell migration towards macrophage-conditioned

media. Data are represented as mean $\pm S D$. Unpaired t-test, $n=6$ replicates from $n=2$

donors, ${ }^{* *} \mathrm{p}<0.01$ 
bioRxiv preprint doi: https://doi.org/10.1101/2021.04.06.438673; this version posted April 8, 2021. The copyright holder for this preprint (which was not certified by peer review) is the author/funder, who has granted bioRxiv a license to display the preprint in perpetuity. It is made

A

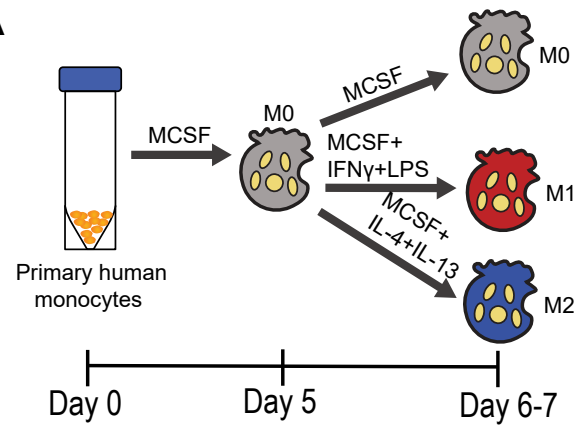

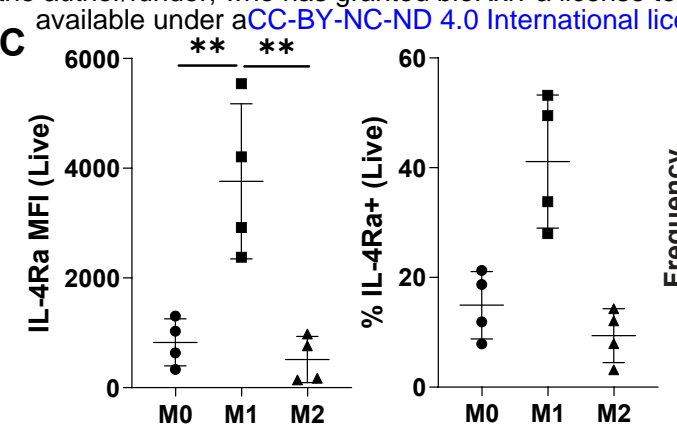

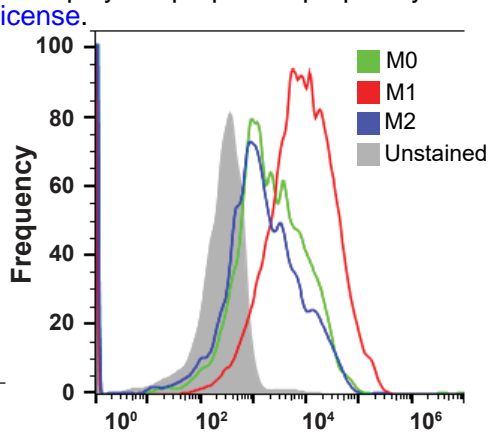

B IL-4 Signaling Genes
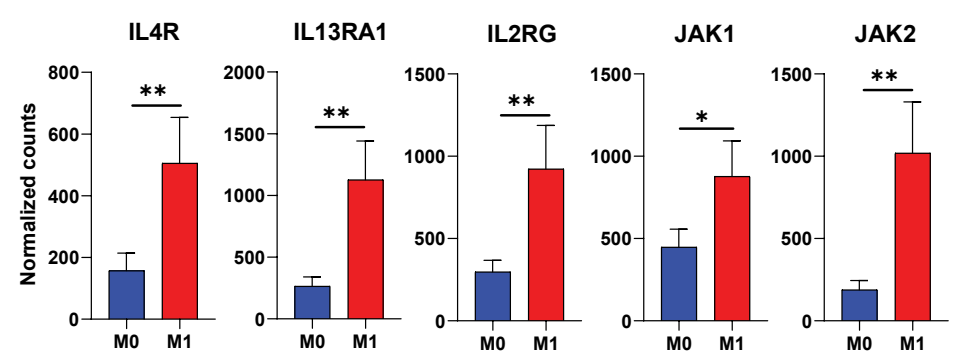

D M2-promoting Receptors

JAK3

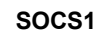

STAT3

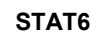

IRF4
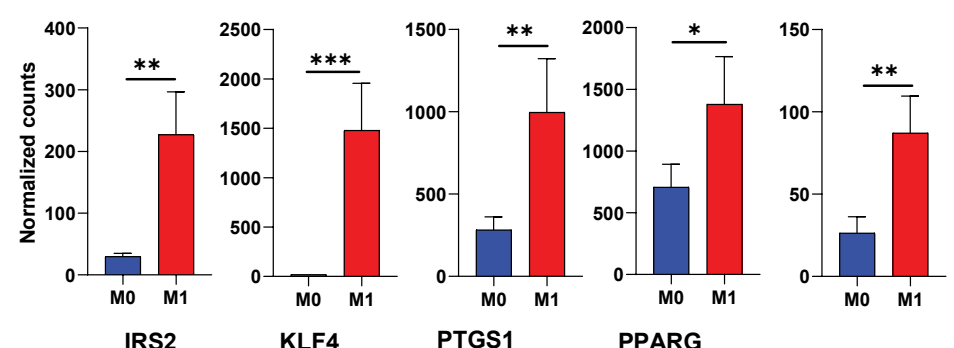

PPARG
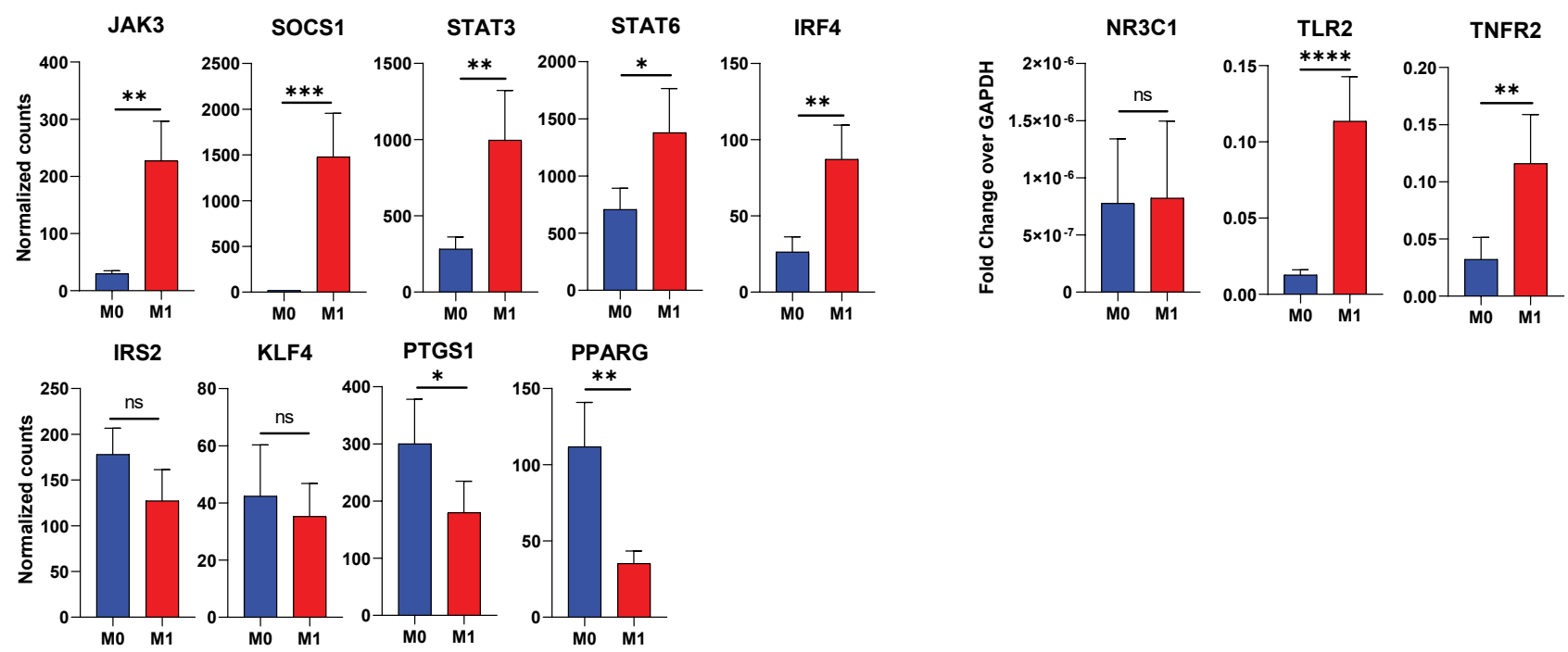
bioRxiv preprint doi: https://doi.org/10.1101/2021.04.06.438673; this version posted April 8, 2021. The copyright holder for this preprint (which

A was not certified by peer review) is the author/funder, who has granted bioRxiv a license to display the preprint in perpetuity. It is made
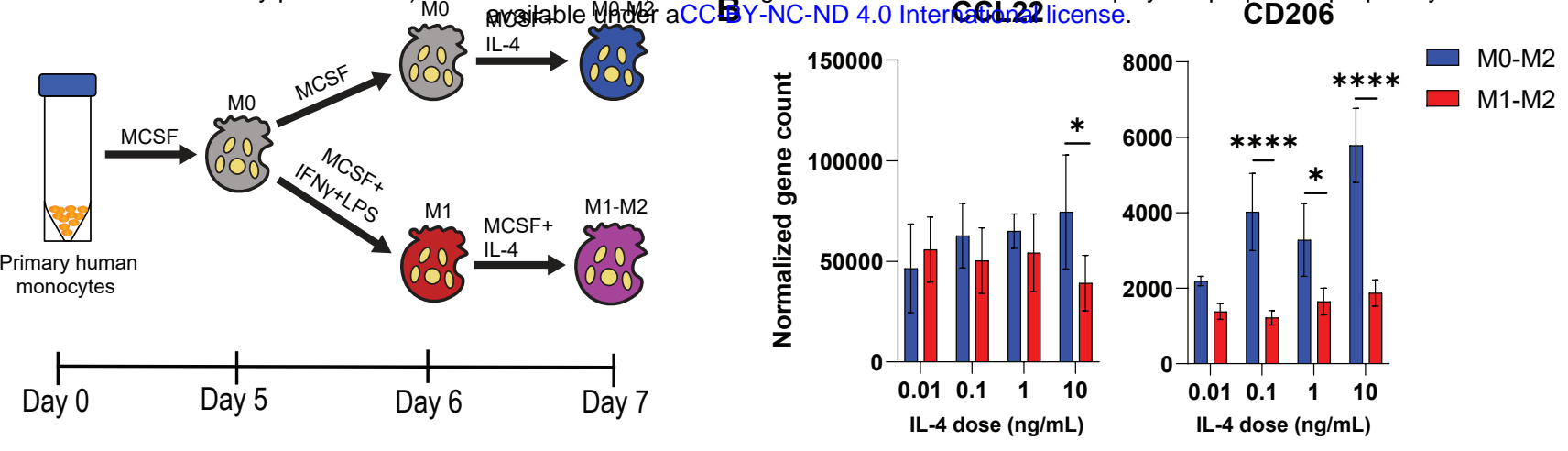

C M2 Markers
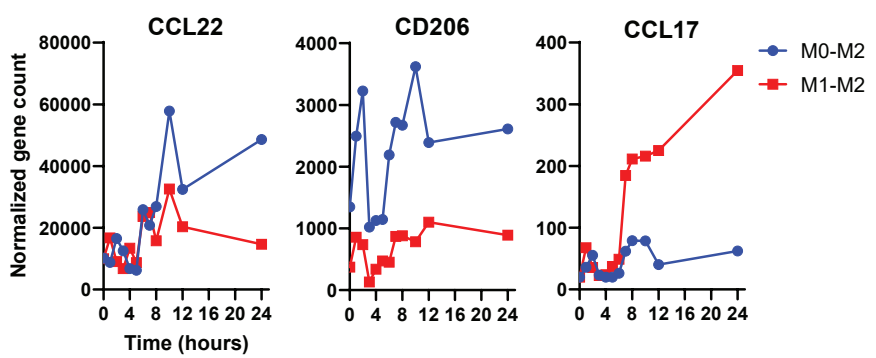

M1 Markers

E IL-4 Signaling Genes
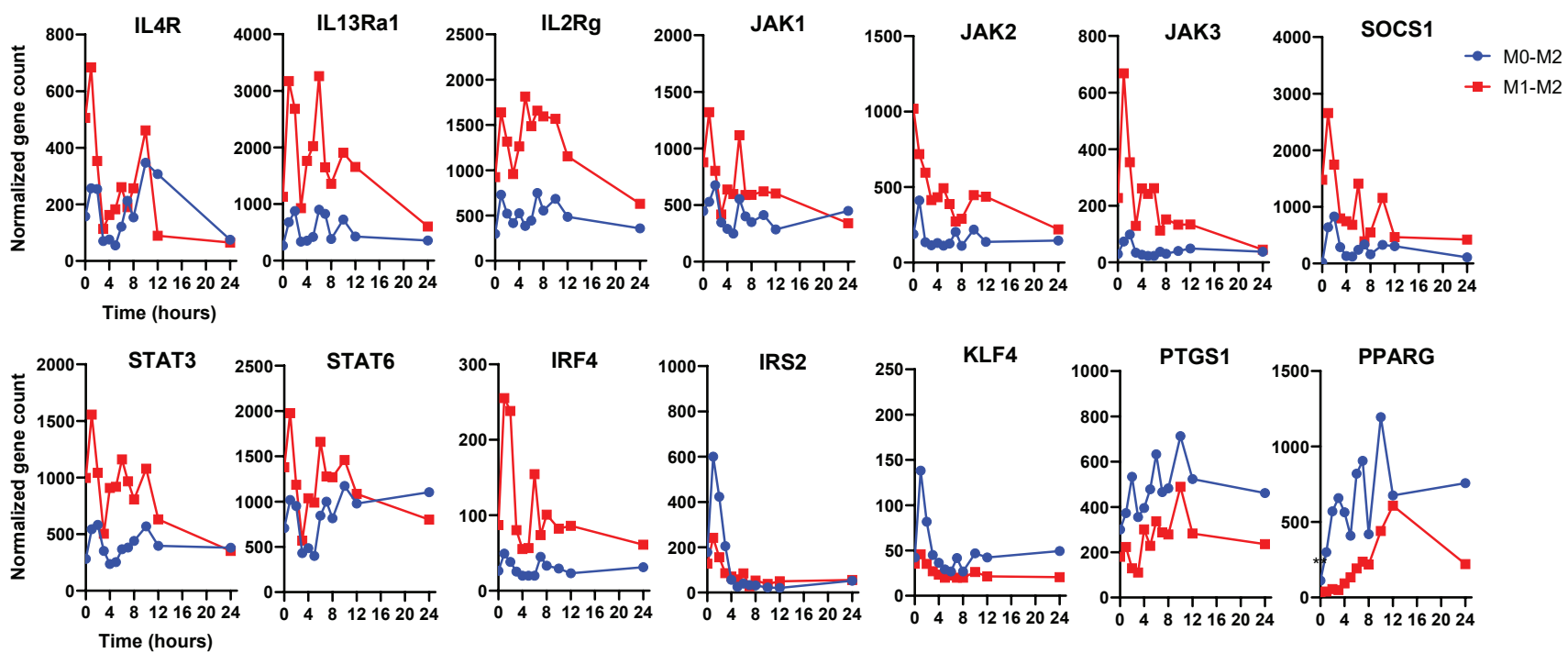
bioRxiv preprint doi: https://doi.org/10.1101/2021.04.06.438673; this version posted April 8, 2021. The copyright holder for this preprint (which

A was not certified by peer review) is the author/funder, who has granted bioRxiv a license to display the preprint in perpetuity. It is made

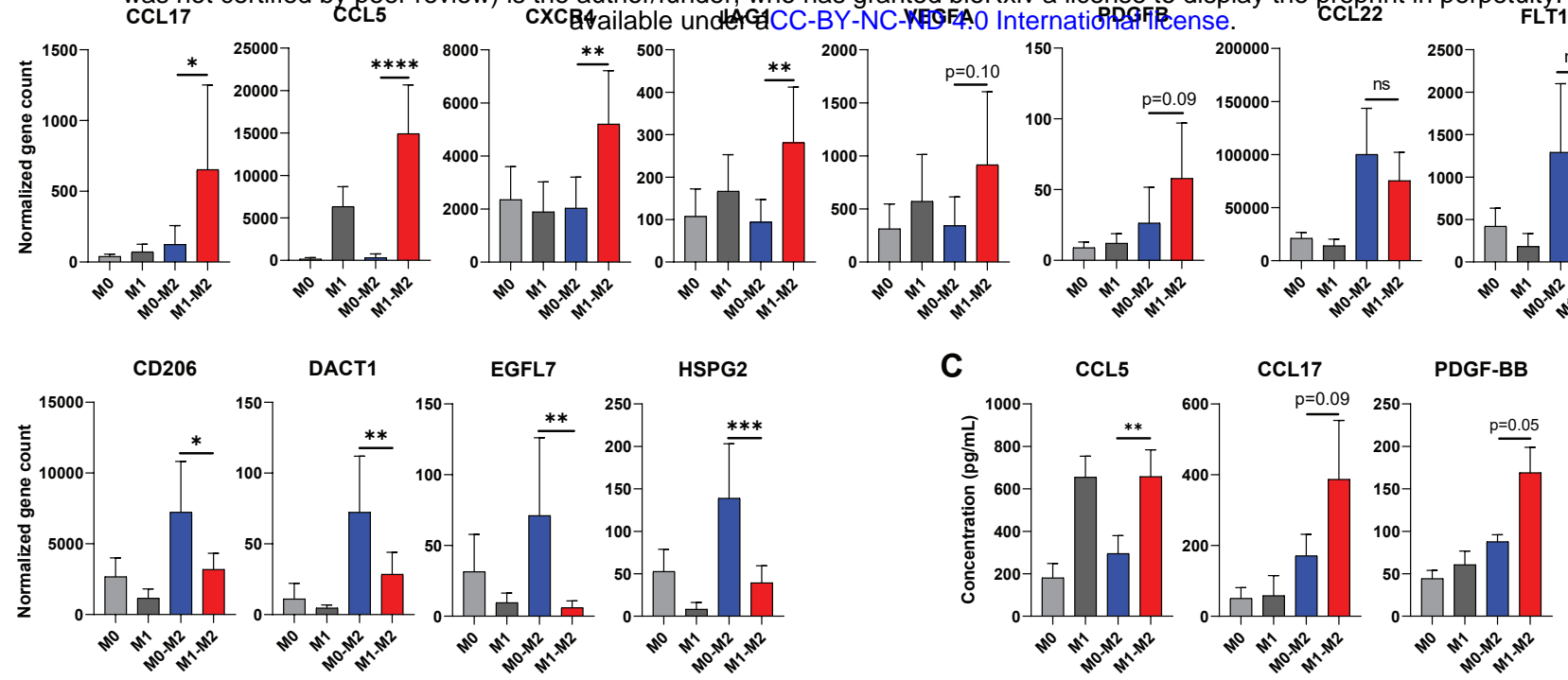

\section{B}

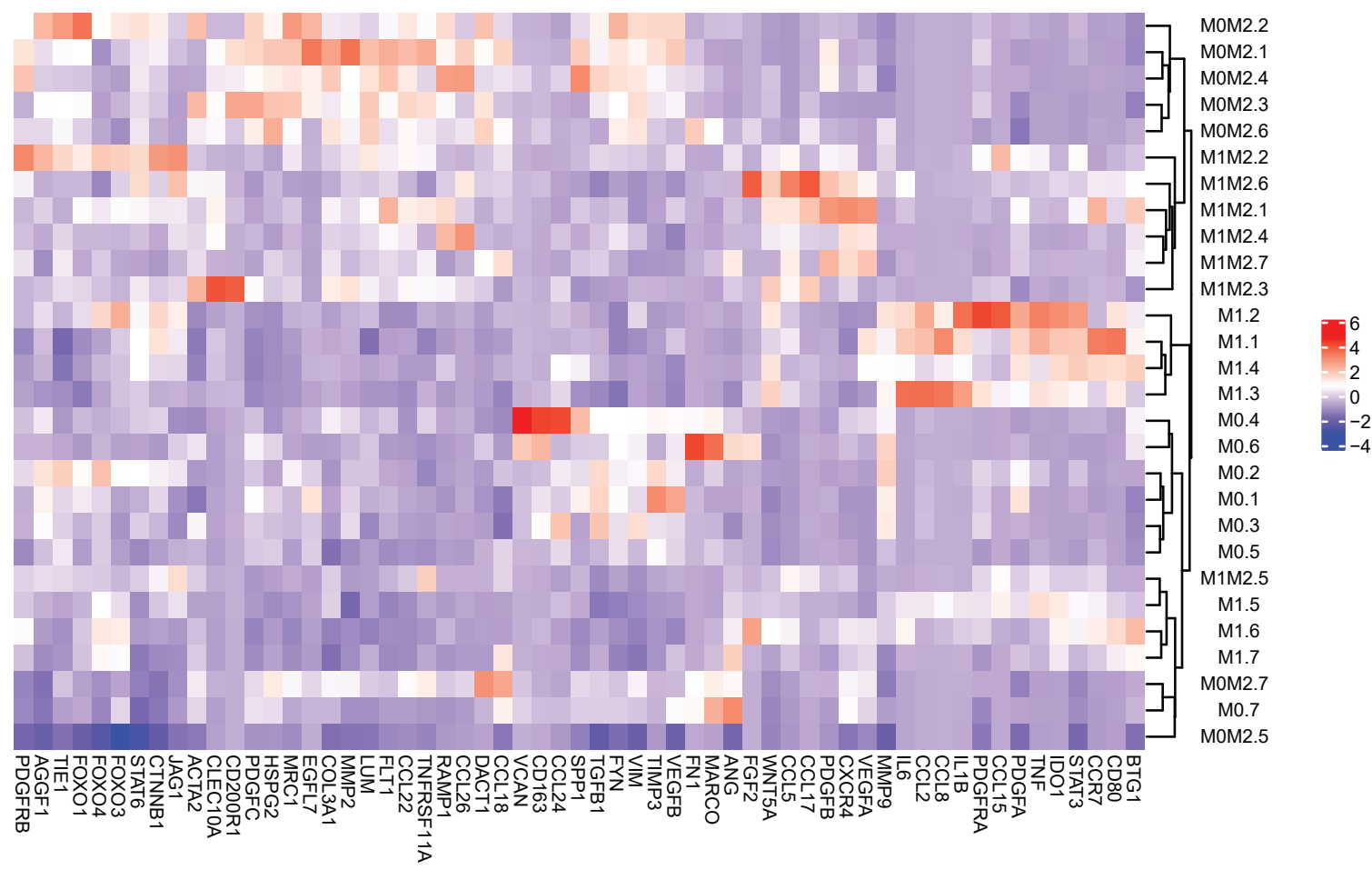

Figure 3a: M0-M2 and M1-M2 expression of M2, angiogenesis, and tissue deposition genes

Statistics: One-way ANOVA with Tukey's post-hoc; $n=7$ donors; ${ }^{*} p<0.05,{ }^{* \star} p<0.01,{ }^{* \star *} p<0.001,{ }^{* \star * *} p<0.0001$; mean w/ SEM 
bioRxiv preprint doi: https://doi.org/10.1101/2021.04.06.438673; this version posted April 8, 2021. The copyright holder for this preprint (which was not certified by peer review) is the author/funder, who has granted bioRxiv a license to display the preprint in perpetuity. It is made available under aCC-BY-NC-ND 4.0 International license.

A Macophage migration

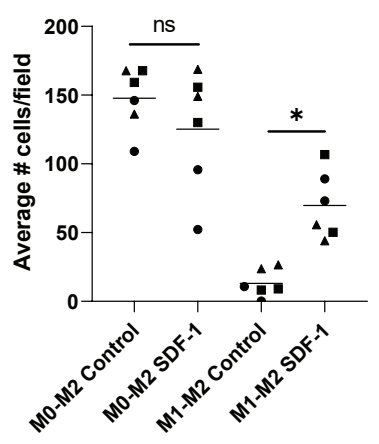

B Macophage migration towards SDF-1a

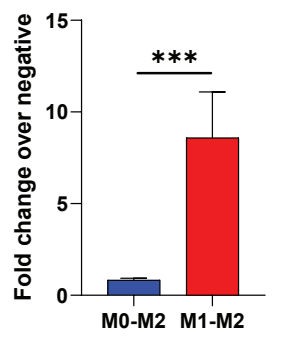

C

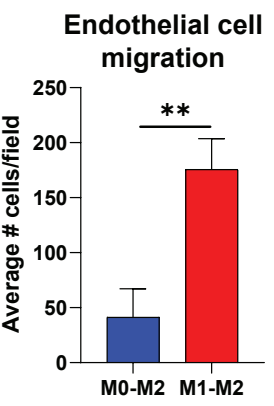

